\title{
Evaluation of Ciclopirox as a Virulence-modifying Agent Against Multidrug Resistant Pseudomonas aeruginosa Clinical Isolates from Egypt
}

\author{
Azza S. Zakaria*, Eva A. Edward, and Nelly M. Mohamed \\ Microbiology and Immunology Department, Faculty of Pharmacy, Alexandria University, Alexandria 21526, Egypt
}

Received: August 8, 2019 / Revised: August 18, 2019 / Accepted: August 20, 2019

\begin{abstract}
Targeting the pathogen viability using drugs is associated with development of drug resistance due to selective pressure. Hence, there is an increased interest in developing agents that target bacterial virulence. In this study, the inhibitory effect of ciclopirox, an antifungal agent with iron chelation potential, on the microbial virulence factors was evaluated in 26 clinical MDR Pseudomonas aeruginosa isolates collected from Alexandria Main University Hospital, a tertiary hospital in Egypt. Treatment with $9 \mu \mathrm{g} / \mathrm{ml}$ ciclopirox inhibited the hemolytic activity in $\mathbf{7 0} \%$ isolates, reduced pyocyanin production, decreased protease secretion in $\mathbf{4 6} \%$ isolates, lowered twitching and swarming motility, and decreased biofilm formation by 1.5- to 4.5-fold. The quantitative real-time PCR analysis revealed that treatment with ciclopirox downregulated the expression levels of alkaline protease (aprA) and pyocyanin (phzA1). Ciclopirox is used to treat hematological malignancies and the systemic administration of ciclopirox is reported to have adequate oral absorption with a satisfactory drug safety profile. It is important to calculate the appropriate clinical dose and therapeutic index to reposition ciclopirox from a topical antifungal agent to a promising virulence-modifying agent agent against $P$. aeruginosa, a problematic Gram-negative pathogen.
\end{abstract}

Keywords: Ciclopirox, virulence factors, Pseudomonas aeruginosa, biofilm, gene expression

\section{Introduction}

In the current battle between humankind and pathogens, it seems that bugs are still having the upperhand. The continuous rise in reported resistance to different antimicrobial agents and the shortage in the development of new antibiotics over the past decades are two facts weighing the results of this battle to the favor of the microorganisms [1]. Since the development of a novel antimicrobial agent may cost millions of dollars and may take a considerable number of years to happen, an alternative approach is becoming nowadays more

\section{*Corresponding author}

Tel: +203 4868482, Fax: +2034871668

E-mail: azza.hanafy@alexu.edu.eg

○ 2019, The Korean Society for Microbiology and Biotechnology and more appealing. This approach intends to repurpose older drugs to combat infections caused by certain problematic pathogens [2] or to hinder the bacterial virulence instead of bacterial viability [1].

One of the old drugs that has come back to the clinical stage is ciclopirox. Ciclopirox is an off-patent antifungal agent that has been developed about forty years ago and which possesses several advantages such as a wide safety margin, a profound efficacy and the ability to affect novel targets including resistant Gram-negative pathogens [2,3]. In Gram-negative bacteria, ciclopirox was reported to affect galactose metabolism, as well as lipopolysaccharide (LPS) biosynthesis; two pathways extremely significant for bacterial growth and virulence [2].

Out of different members of Gram-negative bacteria, 
$P$. aeruginosa has been regarded as a cardinal opportunistic pathogen [4] responsible for about $10-15 \%$ of nosocomial infections all over the world [5]. P. aeruginosa can result in ventilator associated pneumonia, urinary tract infections, multi-organ system failure, burn wounds infection and sepsis in the ICU [6]. The high morbidity and mortality rates associated with $P$. aeruginosa infections are due to the organism's ability to accommodate to environmental changes, to develop resistance to various antimicrobial agents and to express multiple virulence factors [5].

$P$. aeruginosa is characterized by numerous cell-associated virulence factors, such as flagella, pili, biofilm and LPS. Aside from enabling motility, the flagellum indirectly participates in membrane permeabilization [4], while the type IV pili facilitate the bacterial adherence and are in charge of the twitching motility needed for the initial attachment and biofilm development [7]. Besides escaping the host immune system, biofilms possess an antibiotic resistant nature that facilitates the bacterial endurance in chronic infections [4]. The flagellum and type IV pili, together, mediate the swarming motility of $P$. aeruginosa on semisolid surfaces [8]. The LPS of $P$. aeruginosa is invloved in the activation of the host immune responses [4]. This organism expresses, as well, various extracellular virulence factors including proteases, hemolysins, cytotoxin, pyocyanin, siderophores, exotoxin A and exoenzymes [5]. Proteases produced by $P$. aeruginosa play a part in tissue destruction associated with eye and lung infections [4]. A blue redoxactive exoproduct, pyocyanin, is responsible for inducing neutrophil apoptosis and impairing neutrophil-mediated host defenses in vivo [7]. The siderophores are used to scavenge iron required for the organism's respiration and biofilm formation [9]. In addition, $P$. aeruginosa synthesizes a secretory apparatus (Type III) which enables it to inject the toxins from the cytoplasm into the target cell [4], thus, promoting the apoptosis of eukaryotic cells [10].

The present study was designed to evaluate a new role for ciclopirox; a virulence-modifying agent, and to evaluate its efficacy in inhibiting the virulence of selected $P$. aeruginosa clinical isolates collected from Alexandria Main University Hospital (AMUH), a tertiary teaching hospital in Alexandria, Egypt.

\section{Materials and Methods}

\section{Bacterial strains and culture conditions}

Twenty-six $P$. aeruginosa strains isolated from pus, urine, bronchial lavage, pleural fluid and sputum were obtained from AMUH. These were numbered from PA1PA26. All bacteria were stored as frozen stocks in $40 \%$ glycerol at $-80^{\circ} \mathrm{C}$. A fresh culture was obtained by subculturing isolates on LB medium (tryptone 1\%, yeast extract $0.5 \%, \mathrm{NaCl} 1 \%$ and Bacto agar 1.5\%) for $24 \mathrm{~h}$ at $37^{\circ} \mathrm{C}$ prior to each experiment.

\section{Identification of bacteria}

The bacteria were cultured on a selective medium; cetrimide agar base (Himedia, India), then were incubated at $37^{\circ} \mathrm{C}$ for $24 \mathrm{~h}$. The obtained colonies were subcultured and identified by standard microbiological methods [11].

\section{Antibiotic sensitivity test}

Antibiotic sensitivity was carried out by the disc diffusion method according to the Clinical Laboratory Standard Institute (CLSI) [12]. Different antibiotic discs were used; cefepime, ceftazidime, ceftriaxone ciprofloxacin, colistin, gentamycin, lomefloxacin, moxifloxacin, norfloxacin, ofloxacin, piperacillin and tobramycin (BD BBL, Sensi-Disc). Sensitivity test was analyzed for the identified strains by using Müller Hinton agar (Himedia) and incubated at $37^{\circ} \mathrm{C}$ for $24 \mathrm{~h}$.

\section{Reagents and antimicrobial agent}

All reagents and chemicals used were of a pure pharmaceutical grade. Ciclopirox olamine was purchased as Batrafen solution (10 mg/ml) (Global Napi Pharmaceuticals, Egypt) and was diluted in sterile water to the required concentration immediately prior to each experiment.

\section{Determination of Minimum Inhibitory Concentration (MIC) of ciclopirox}

Ciclopirox MICs were determined using microbroth dilution protocols performed in accordance with CLSI [13]. A volume of $100 \mu \mathrm{l}$ of each bacterial culture (grown in double strength nutrient broth (Oxoid, USA) and adjusted to $0.5 \times 10^{6} \mathrm{CFU} / \mathrm{ml}$ using the $0.5 \mathrm{McF}$ arland standard) was added to 96 -well polystyrene microtiter plate. Aliquots of $100 \mu \mathrm{l}$ of serial dilutions of ciclopirox 
$(2048 \mu \mathrm{g} / \mathrm{ml})$ prepared in sterile water (the tested concentrations ranged from 1024 to $2 \mu \mathrm{g} / \mathrm{ml}$ ) were added to each well and incubated at $37^{\circ} \mathrm{C}$ for $24 \mathrm{~h}$. MIC was measured in triplicate and determined as reported before [14].

\section{Phenotypic detection of different virulence factors \\ Crystal violet biofilm assay. Quantitative determina-} tion of biofilm formation before and after treatment with ciclopirox was tested by crystal violet microtiter plate assay [15, 16]. Briefly, a 96-well polystyrene plates were inoculated with a $100 \mu \mathrm{l}$ culture of each of the isolates in double strength tryptic soy broth (Oxoid) to reach a final concentration of $0.5 \times 10^{6} \mathrm{CFU} / \mathrm{ml}$. A volume of $100 \mu \mathrm{l}$ of $18 \mu \mathrm{g} / \mathrm{ml}$ ciclopirox was then added to each well [2]. Control wells were also prepared without ciclopirox addition. The plates were incubated aerobically for $48 \mathrm{~h}$ without shaking at $37^{\circ} \mathrm{C}$. Next, wells were gently decanted and rinsed three times with sterile PBS ( $\mathrm{pH} 7.2$ ). After air drying, the wells were fixed with $100 \mu \mathrm{l}$ of $99 \%$ methanol per well for $20 \mathrm{~min}$. Biofilms were detected by staining the wells with $200 \mu \mathrm{l}$ of $0.1 \%$ crystal violet (Sigma) for 15 min at room temperature and then washed thoroughly with distilled water to remove any residual dye. Then, $200 \mu \mathrm{l}$ of glacial acetic acid (33\%) were added and left for $30 \mathrm{~min}$ to elute crystal violet from the biofilms and the absorbance of the solubilized dye was measured at $520 \mathrm{~nm}$ using a microtiter plate reader. Each data point was averaged from three replicate wells and the following classification was used for the determination of biofilm formation: no biofilm production (ODs = ODnc), weak biofilm production (ODnc $<$ ODs $\leq 2$ ODnc), moderate biofilm production (2ODnc $<$ ODs $\leq 40 D n c)$ and strong biofilm production (4ODnc $<$ ODs) [15].

Hemolytic activity on blood agar. $P$. aeruginosa isolates, before and after treatment with $9 \mu \mathrm{g} / \mathrm{ml}$ ciclopirox, were streaked onto blood agar medium (Nutrient agar supplemented with $5 \%$ sheep blood, Oxoid). The formation of a hemolytic zone was indicative of hemolytic activity of tested isolates. Average hemolytic zones around the developed colonies of the control and treated isolates were then recorded after $24 \mathrm{~h}$ incubation at $37^{\circ} \mathrm{C}$.

Protease assay. Protease activity was determined using skimmed milk agar plates containing $10 \% \mathrm{w} / \mathrm{v}$ of non-fat dry milk and 1\% w/v of Bacto-agar [17]. Aliquots of $40 \mu \mathrm{l}$ from overnight culture of $P$. aeruginosa isolates, before and after treatment with $9 \mu \mathrm{g} / \mathrm{ml}$ of ciclopirox, were added into previously cut wells in the milk agar plates and incubated at $37^{\circ} \mathrm{C}$ for $24 \mathrm{~h}$. Protein digestion was shown as a clear zone around the wells. The average zone diameter of two independent readings was then recorded.

\section{Qualitative and quantitative measurement of pyocyanin production}

Pyocyanin pigment production was visualized by spreading $P$. aeruginosa isolates (without or with $9 \mu \mathrm{g} /$ $\mathrm{ml}$ ciclopirox) on $\mathrm{P}$ agar plates (peptone $20 \mathrm{~g} / \mathrm{l}$, magnesium chloride $1.40 \mathrm{~g} / \mathrm{l}$, potassium sulfate $10 \mathrm{~g} / \mathrm{l}$, and Bacto agar $15 \mathrm{~g} / \mathrm{l}$ (Oxoid). The final $\mathrm{pH}$ was adjusted to 7.2. This was followed by $24 \mathrm{~h}$ incubation at $37^{\circ} \mathrm{C}$. Pyocyanin producing isolates manifested deep blue colonies on $\mathrm{P}$ agar plates [18, 19].

The quantitative pyocyanin assay of $P$. aeruginosa was adopted from Essar et al. [20, 21]. After growth for $24 \mathrm{~h}$ in LB medium (without or with $9 \mu \mathrm{g} / \mathrm{ml}$ ciclopirox), culture supernatants were extracted with 1-2 ml chloroform. The tubes were vortexed for a few seconds until the chloroform layer turned blue due to pyocyanin diffusion. The chloroform was acidified with a few drops of $\mathrm{HCl}$, which resulted in a rapid change in color from blue to red, then analyzed spectrophotometrically [22]. All experiments were done in triplicates.

\section{Bacterial motility}

Swarming and twitching motilities of the tested $P$. aeruginosa isolates, before and after treatment with ciclopirox, were assessed as described previously [23]. Overnight cultures grown in LB were directly transferred to twitching plates (1.0 g tryptone, $0.5 \mathrm{~g}$ yeast extract, $0.5 \mathrm{~g} \mathrm{NaCl}, 1.0 \mathrm{~g}$ Bacto agar in $100 \mathrm{ml}$ distilled water) by using sterile toothpicks. For the swarming media plates $(0.8 \mathrm{~g}$ nutrient broth N.2, $0.5 \mathrm{~g}$ glucose, $0.5 \mathrm{~g}$ Bacto agar in $100 \mathrm{ml}$ distilled water), the bacterial culture was diluted 1:100 in fresh LB medium and an aliquot of $20 \mu \mathrm{l}$ was spotted onto the surface of the plates.

After $16 \mathrm{~h}$ of growth at $37^{\circ} \mathrm{C}$, swarming motilities were directly observed at the air-agar interface, while twitching motility was measured at the agar-plastic interface 
Table 1. Primers of the selected genes chosen for transcript analysis using quantitative RT-PCR.

\begin{tabular}{cclcc}
\hline Gene & Orientation & \multicolumn{1}{c}{ Sequence $\left(5^{\prime}\right.$-3') } & Product size (bp) & Reference \\
\hline aprA & $\mathrm{F}$ & GCTTCAGCCAGAACCAGAAGAT & 78 & 24 \\
& $\mathrm{R}$ & TCGACACATTGCCCTTCAAC & & 24 \\
phzA1 & $\mathrm{F}$ & TAAAACGTAATCGCGAGTTCATG & 74 & 25 \\
& $\mathrm{R}$ & TTTTATTTGCGAACGGCTATT & & 123 \\
\end{tabular}

after the removal of the agar layer and staining with crystal violet [23]. Each experiment was performed using at least two independent cultures.

\section{Molecular quantification of aprA and phzA1 genes by Real-time PCR}

Quantitative real-time PCR was conducted for ten isolates selected according to the results of the phenotypic detection of their virulence factors using the Applied Biosystems 7500 Real-Time PCR System (Thermo Fisher Scientific Inc., USA) and used to assess the localized expression of aprA gene (encoding alkaline protease) and phzA1 gene (necessary for pyocyanin biosynthesis) before and after treatment with $9 \mu \mathrm{g} / \mathrm{ml}$ ciclopirox. Gene specific primer pairs were synthesized in Macrogen, Korea, based on the previously published sequences [24]. The data were normalized against the house keeping gene Rpsl [25]. The primers of aprA, phzA1 and Rpsl gene for the RT-PCR amplification of cDNA are listed in Table 1.

\section{RNA isolation and reverse transcription}

Total RNA was extracted from each overnight subculture of selected isolates using the TRIzol ${ }^{\circledR}$ MaxTM Bacterial RNA Isolation Kit (Ambion by Life Technologies) in accordance with the manufacturer's instructions. RNA was quantified using Jenway Genova Nano, Keison products, UK.

Reverse transcription was carried out using the TOPreal $^{\mathrm{TM}}$ One step RT qPCR Kit (Enzynomics). The real time PCR mixture consisted of $1 \mu \mathrm{l}$ of TOPreal ${ }^{\mathrm{TM}}$ One step RT qPCR Enzyme Mix, $10 \mu \mathrm{l}$ of $2 \mathrm{X}$ TOPreal ${ }^{\mathrm{TM}}$ One step RT qPCR Reaction Mix, $1 \mu$ l of each primer, $1 \mu \mathrm{l}$ of total RNA, and sterile DNAse-free water made up to a total reaction volume of $20 \mu \mathrm{l}$.

After a preliminary holding step at $50^{\circ} \mathrm{C}$ for $30 \mathrm{~min}$, the cycling conditions used for the PCR reaction included an initial denaturation step at $95^{\circ} \mathrm{C}$ for $10 \mathrm{~min}$, followed by 40 cycles of denaturation at $95^{\circ} \mathrm{C}$ for $5 \mathrm{sec}$ and annealing/extension at $60^{\circ} \mathrm{C}$ for $30 \mathrm{sec}$. A negative (no template) control containing sterile DNAse-free water instead of the total RNA template was included in each RT- PCR run. Samples were run in triplicate; virtually all individual results were within $0.5 \mathrm{Ct}$ units of the averaged triplicate value.

Melting curves were then analyzed (to ensure the absence of primer dimers and other artifacts) in one cycle of $94^{\circ} \mathrm{C}, 53^{\circ} \mathrm{C}$ and $94^{\circ} \mathrm{C}$, one minute each. Amplification curves and cycle threshold $(\mathrm{Ct})$ values were determined by Stratagene MX3005P software. The Ct values for each gene amplification were converted into fold differences after normalization to the $\mathrm{Ct}$ of the Rpsl gene and according to the relative quantification method described previously [26].

Normalized expression of aprA and phzA1 in the ten selected isolates was calibrated against corresponding mRNA expression of the same isolate without ciclopirox treatment. Results were presented as the relative expression of the mRNA compared to the untreated isolate.

\section{Statistical analysis}

Data of the RT-PCR data were expressed as means \pm S.D. For multi-variable comparisons, one-way ANOVA was conducted, followed by Bonferroni testing using Prism 3 GRAPHPAD computer program. Differences were considered significant at $p$-value $<0.05$. The data used in this experiment represents the mean of 3 biological replicates.

\section{Results}

\section{Isolation and Identification}

A total of $26 P$. aeruginosa clinical isolates were collected from AMUH: 8 samples were obtained from pus, 8 
Table 2. Minimum inhibitory concentrations (MICs) of ciclopirox against $P$. aeruginosa $(\mathrm{N}=26)$ and their joined resistance pattern.

\begin{tabular}{cl}
\hline $\begin{array}{c}\text { MIC of ciclopirox } \\
(\mu \mathrm{g} / \mathrm{ml}) \\
(\text { No. of isolates) }\end{array}$ & \multicolumn{1}{c}{ Joined resistance pattern } \\
\hline $8(9)$ & TOB, GM, CAZ, CRO, CIP \\
$16(10)$ & TOB, GM, CAZ, CRO, FEP, PIP, CIP \\
$32(6)$ & TOB, GM, CAZ, CRO, FEP, PIP, CIP, OFX, CL \\
$64(1)$ & TOB, GM, CAZ, CRO, FEP, CIP, OFX, CL, NOR, \\
& MFX, LOM \\
\hline
\end{tabular}

TOB; Tobramycin, GM; Gentamycin, CAZ; Ceftazidime, CRO; Ceftriaxone, FEP; Cefepime, PIP; Piperacillin, CIP; Ciprofloxacin, OFX; Ofloxacin, $\mathrm{CL}$; Colistin, NOR; Norfloxacin, MFX; Moxifloxacin and LOM; Lomefloxacin.

from urine, 6 from sputum, 3 from bronchial lavage fluids and one isolate from the pleural fluid. Collected isolates were subjected to microscopic examination and their identity was confirmed by using preliminary and selective biochemical tests [11].

\section{Ciclopirox MIC and antibiotic resistance profile of clinical isolates}

The MICs of ciclopirox and the joined resistance profile data of the 26 clinical isolates are presented in Table 2. Overall, there was a clear correlation between the resistance of the strains to different antibiotics and the corresponding MICs of ciclopirox. The MIC values of ciclopirox against the tested isolates ranged from $8 \mu \mathrm{g} /$ $\mathrm{ml}$ to $64 \mu \mathrm{g} / \mathrm{ml}$.

The clinical isolates exhibited different antibiotic resistance patterns. More than $73 \%$ of the isolates had ciclopirox MICs of $\leq 16 \mu \mathrm{g} / \mathrm{ml}$. All the isolates under test were resistant to ceftazidime, ceftriaxone, tobramycin, gentamycin and streptomycin. Sixty-two percent of the isolates were resistant to ciprofloxacin while only seven isolates (27\%) shared ofloxacin resistance (Table 2). However, most of the isolates tested (73\%) were found to be susceptible to colistin.

\section{Phenotypic detection of virulence factors}

In the present study, $92 \%$ of the strains were biofilm formers. The majority of the isolates tested were moderate biofilm formers (20/26) (Fig. 1) and they were distributed among different specimens. Only three isolates were found to be strong biofilm formers, one isolated

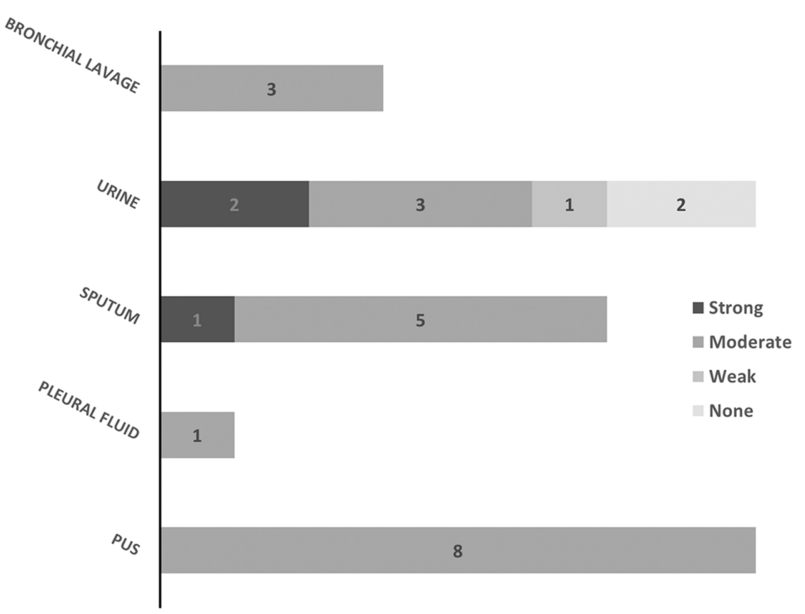

Fig. 1. Distribution of isolates' biofilm strength among different sample sites using crystal violet biofilm assay.

from sputum and two from urine samples. No significant correlation was found relating the collection sample site and biofilm formation (Fig. 1). Furthermore, no detected relationship between the biofilm intensity and the resistance pattern of the organisms was observed.

Changes in the virulence pattern of the studied $P$. aeruginosa clinical isolates upon ciclopirox treatment are shown in Table 3. All of the twenty-six tested $P$. aeruginosa isolates were found to possess hemolytic activity before treatment with ciclopirox olamine, while about $70 \%$ of the isolates lost their activity after treatment. When testing pyocyanin production, 24 isolates (92.3\%) and 3 isolates (11.5\%) were found to be pyocyanin producers before and after ciclopirox treatment, respectively. As for protease production, a difference of $5 \mathrm{~mm}$ or more in proteolytic zone was considered an acceptable decrease in protease production [27]. Twelve isolates (46\%) exhibited a prominent reduction in protease secretion upon ciclopirox treatment while 5 isolates totally lost their protease production ability after treatment (Fig. 2). A total of 24 and 20 isolates were found to be positive for twitching and swarming motility, respectively. Furthermore, 6 and 10 isolates lost their twitching and swarming motility, respectively, upon ciclopirox treatment (Table 3).

Ten isolates were selected for further tests since they displayed significant changes in virulence tests after treatment with $9 \mu \mathrm{g} / \mathrm{ml}$ of ciclopirox. The MIC of ciclopirox against these isolates ranged from 16-64 $\mu \mathrm{g} /$ $\mathrm{ml}$. The quantitative fold decrease in their biofilm forma- 
Table 3. Effect of ciclopirox olamine on different virulence factors of $P$. aeruginosa clinical isolates.

\begin{tabular}{|c|c|c|c|c|c|c|c|c|c|c|}
\hline \multirow{2}{*}{$\begin{array}{l}\text { Isolate } \\
\text { code }\end{array}$} & \multicolumn{2}{|c|}{ Swarming } & \multicolumn{2}{|c|}{ Twitching } & \multicolumn{2}{|c|}{ Hemolysis } & \multicolumn{2}{|c|}{ Pyocyanin production } & \multicolumn{2}{|c|}{ Protease production ${ }^{* *}$} \\
\hline & $U$ & $T^{*}$ & $U$ & $\mathrm{~T}$ & $U$ & $\mathrm{~T}$ & $U$ & $\mathrm{~T}$ & $U$ & $\mathrm{~T}$ \\
\hline PA1 & + & - & + & - & + & - & + & - & 11 & 10 \\
\hline PA2 & + & + & + & + & + & + & + & - & 24 & 20 \\
\hline PA3 & + & - & + & - & + & - & + & - & 20 & 11 \\
\hline PA4 & + & - & + & - & + & + & + & - & 18 & 16 \\
\hline PA5 & + & + & - & - & + & + & + & - & 22 & 16 \\
\hline PA6 & + & - & + & - & + & + & + & + & 20 & 19 \\
\hline PA7 & - & - & + & - & + & - & - & - & 14 & 11 \\
\hline PA8 & - & - & + & + & + & - & + & - & 21 & 8 \\
\hline PA9 & + & + & + & + & + & + & + & - & 22 & 20 \\
\hline PA10 & - & - & + & - & + & - & + & - & 20 & 10 \\
\hline PA11 & + & - & + & + & + & - & + & - & 19 & 0 \\
\hline PA12 & + & + & + & + & + & - & + & - & 19 & 0 \\
\hline PA13 & + & - & + & + & + & - & + & - & 20 & 11 \\
\hline PA14 & + & + & + & + & + & + & + & - & 23 & 14 \\
\hline PA15 & + & + & + & + & + & - & + & + & 21 & 15 \\
\hline PA16 & - & - & + & + & + & - & + & - & 18 & 11 \\
\hline PA17 & + & - & + & - & + & - & + & - & 19 & 12 \\
\hline PA18 & + & + & + & + & + & + & + & + & 18 & 13 \\
\hline PA19 & + & + & - & - & + & + & + & - & 18 & 18 \\
\hline PA20 & + & + & + & + & + & - & - & - & 18 & 11 \\
\hline PA21 & - & - & + & + & + & - & + & - & 20 & 12 \\
\hline PA22 & + & - & + & + & + & - & + & - & 21 & 12 \\
\hline PA23 & + & - & + & + & + & - & + & - & 18 & 0 \\
\hline PA24 & - & - & + & + & + & - & + & - & 20 & 0 \\
\hline PA25 & + & - & + & + & + & - & + & - & 18 & 9 \\
\hline PA26 & + & - & + & + & + & - & + & - & 21 & 0 \\
\hline
\end{tabular}

*U (Untreated sample), $\mathrm{T}$ (treated sample).

**Zone diameter in $\mathrm{mm}$.

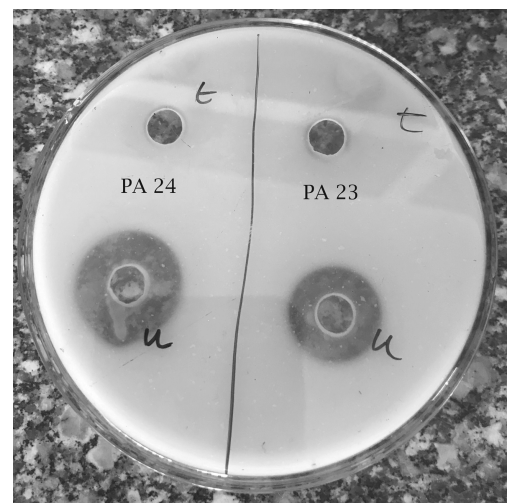

Fig. 2. Loss of protease activity in isolates PA23 and PA24 where $(u)$ represents supernatant of untreated corresponding isolate and $(t)$ represents supernatant of corresponding isolate treated with $9 \mu \mathrm{g} / \mathrm{ml}$ of ciclopirox olamine. tion and pyocyanin production was demonstrated in Fig. 3. The selected strains were either moderate or strong biofilm formers. After ciclopirox overnight treatment, all of the isolates became non-biofilm formers with a decrease in biofilm formation ranging from 1.5- to 4.5fold (Fig. 3). Among our selected strains, pyocyanin was significantly produced before treatment with ciclopirox. That was manifested as a blue green pigment around the colonies grown on $\mathrm{P}$ agar plates and quantitatively upon extraction with chloroform. However, after ciclopirox treatment, there was a significant reduction in the amount of the pyocyanin produced ranging from 4fold decrease in case of isolate PA26 to more than 12-fold decrease in case of PA10 (Fig. 3). 


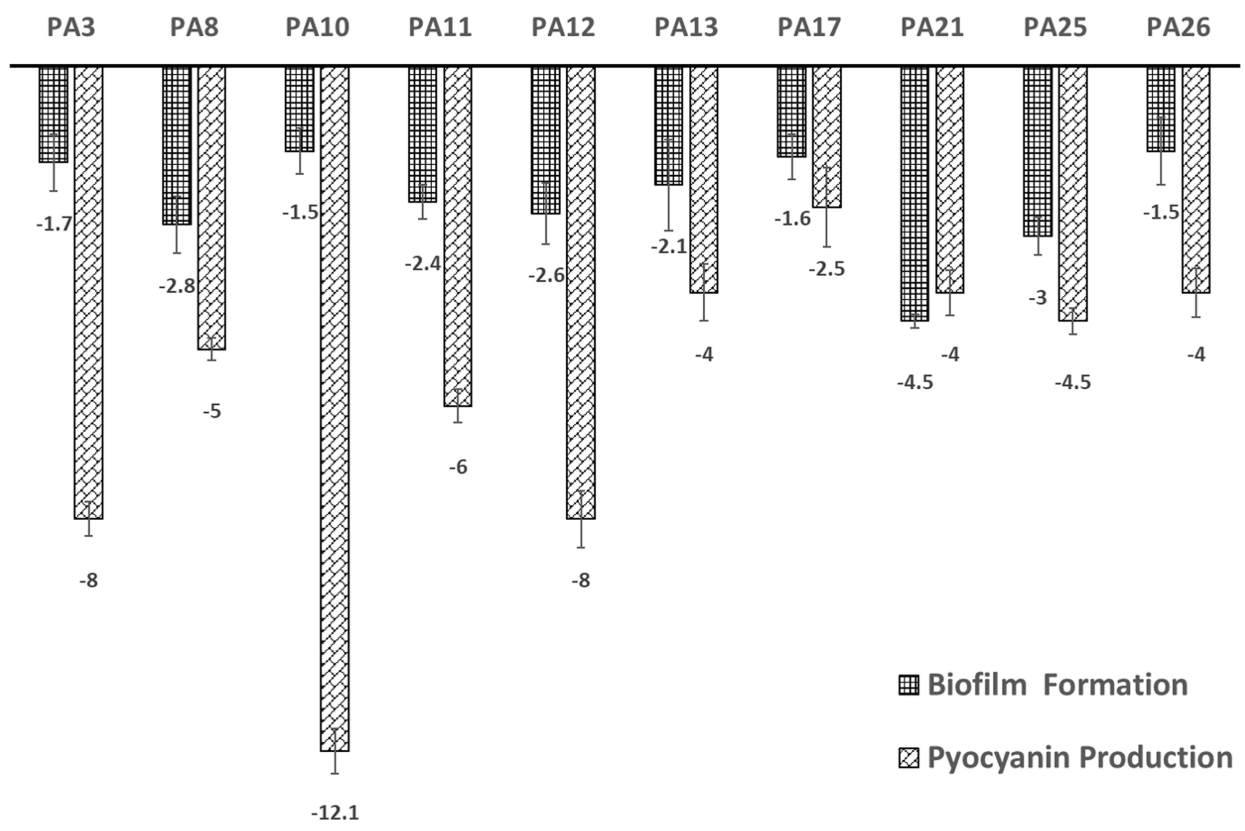

Fig. 3. Fold change in biofilm formation and pyocyanin production after overnight treatment with $9 \mu \mathrm{g} / \mathrm{ml}$ ciclopirox among ten $P$. aeruginosa selected isolates. The error bars represent SDs.

\section{Effect of ciclopirox olamine on aprA and phzA1 gene expression}

The effect of overnight treatment with $9 \mu \mathrm{g} / \mathrm{ml}$ ciclopirox on the expression of the virulence genes aprA (alkaline protease gene) (Fig. 4A) and phzA1 (pyocyanin biosynthesis gene) (Fig. 4B) among ten selected isolates of $P$. aeruginosa grown at $37^{\circ} \mathrm{C}$ was measured by quantitative RT-PCR (Fig. 4).

The levels of aprA and phzA1 gene expression were normalized to the levels of Rpsl gene expression and then compared with the levels of expression in corresponding untreated isolates. The transcripts of target
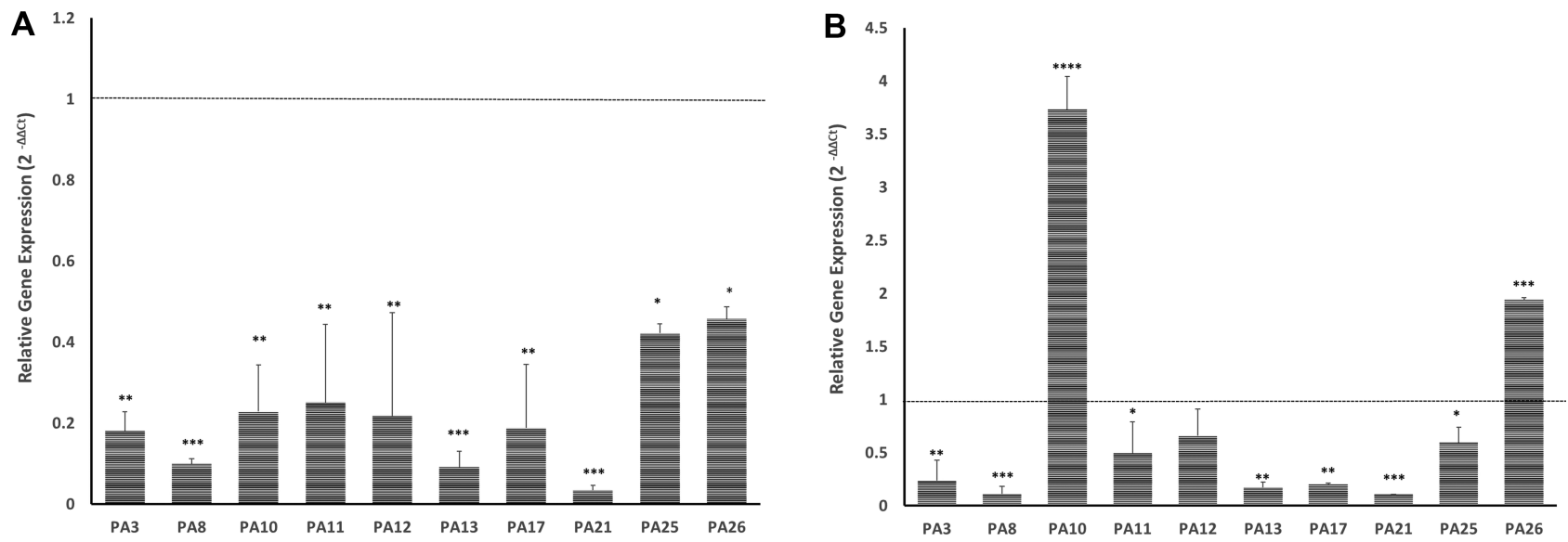

Fig. 4. Relative gene expression of aprA (A) and phzA1 (B) determined by quantitative reverse transcriptase PCR for $P$. aeruginosa cultures. Total RNAs were prepared from ten selected isolates after overnight treatment with $9 \mu \mathrm{g} / \mathrm{ml}$ ciclopirox and calibrated against the corresponding untreated isolate. The levels of transcripts were normalized to the level of $r p s /$ expression then compared to the level of expression by untreated cultures. No effect of the treatment corresponds to relative expression of 1 . Results are expressed as the means and standard deviations of three independent determinations. The error bars represent SDs. The $p$-values indicate significance where ${ }^{*} p<0.05,{ }^{* *} p<0.01,{ }^{* * *} p<0.001$ and ${ }^{* * *} p<0.0001$. 
genes were calculated using the Pfaffle method or $\Delta \Delta \mathrm{Ct}$ method [26].

The results depicted in Fig. 4A clearly show that a statistically significant but variable downregulation in the expression of aprA gene occurred upon treating the samples with subinhibitory concentration of ciclopirox with fold change ranging from 0.45 - to 0.03 -fold. The $p$-value was $<0.05$ among isolates PA25 and PA26, while isolates PA8, PA13 and PA21 showed a highly significant reduction in the expression of the target gene with a $p$ value of $<0.001$ compared to no effect of the treatment which corresponds to relative expression of 1 .

The effect of subinhibitory concentration of ciclopirox on the ten selected pseudomonas cultures displayed different results as respect to the relative expression of phzA1 gene as shown in Fig. 4B. Isolates PA10 and PA26 showed an unexpected significant upregulation in the gene under test compared to the expression of the isolates without treatment with fold changes in expression equals to 3.73 and 1.93, respectively. In contrast, the significance of ciclopirox treatment of the other isolates ranged from highly downregulation values in both PA8 and PA21 to acceptable values, though significant, in case of PA25 and PA1. However, no significant effect was observed on the expression of isolate PA12.

\section{Discussion}

$P$. aeruginosa is one of the clinically significant opportunistic pathogens causing infections that are lifethreatening, and in most cases, difficult or challenging to eradicate [28]. The problem is aggravated by the fact that most of the isolated $P$. aeruginosa strains are reported to be multidrug resistant (MDR) ones [29]. In South Asia, the Middle East and the Mediterranean, modern medicine is already under threat from these MDR $P$. aeruginosa isolates [30].

In the present study, 26 clinical isolates of $P$. aeruginosa collected from hospitalized patients admitted to AMUH were found to be resistant to at least 3 classes of antibiotics and, thus, were recognized as MDR isolates [31]. A study conducted in the ICU of a parallel tertiary hospital, Alexandria University Students' Hospital, reported a percentage of $19 \%$ of MDR P. aeruginosa [32]. The tested isolates in the present study remained susceptible to colistin, an antibiotic described as salvage therapy for $P$. aeruginosa infections [33, 34]. However, because of its significant nephrotoxicity and neurotoxicity, colistin has a limited clinical use [35]. The lack of appearance of new classes of antibiotics for the treatment of Gram-negative infections for more than 40 years [36] has outlined the importance on focusing on agents that disarm bacteria, thereby decreasing or completely nullifying their pathogenicity.

Ciclopirox, an old antifungal agent, has been evaluated in this study for its ability to inhibit the virulence factors expressed by $P$. aeruginosa isolates under investigation. Ciclopirox was previously reported to inhibit the growth of some Gram-negative bacteria [37, 38], but its efficacy had not been widely tested against antibiotic resistant bacteria. In the current study, the $\mathrm{MIC}_{50}$ of ciclopirox was found to be $16 \mu \mathrm{g} / \mathrm{ml}$ for MDR $P$. aeruginosa. An MIC range of 10 to $>30 \mu \mathrm{g} / \mathrm{ml}$ was reported by CarlsonBanning et al. for clinical P. aeruginosa isolates [2]. A number of observations suggested that ciclopirox olamine might act as a chelator of iron ions [39-41], this could explain the inhibition of the cell growth observed in this work.

A concentration of $9 \mu \mathrm{g} / \mathrm{ml}$ of ciclopirox was used in this study to test its effect on virulence factors without affecting the bacterial growth. Hemolytic phospholipases secreted by Pseudomonas species are reported to directly cause lyse of human and sheep erythrocytes [42]. A percentage of $70 \%$ of tested isolates lost their hemolytic activity after ciclopirox treatment (Table 3). However, among Candida albicans isolates, subinhibitory concentration of ciclopirox treatment caused a strong upregualtion of secreted phospholipases compared to the untreated ones [43].

The blue-green pyocyanin siderophore produced by $P$. aeruginosa cultures has been shown in vitro to induce apoptosis in neutrophils, as well as to inhibit the phagocytosis of apoptotic bodies by macrophages [44]. A percentage of $93 \%$ of the tested isolates produced pyocyanin. This percentage decreased to $12 \%$ upon ciclopirox treatment (Table 3) with a quantitative reduction ranging from 4-fold to more than12-fold (Fig. 3).

The proteases secreted by $P$. aeruginosa have established roles in sepsis and ocular infections where they can degrade immunoglobulins and fibrin and disrupt epithelial tight junctions [45]. A total of 12 isolates (46\%) exhibited a prominent reduction in protease secretion 
and 5 isolates totally lost their protease production ability after treatment (Fig. 2). A similar finding has been reported when ciclopirox was tested against $C$. albicans where a decrease in protease secretion was reported [43]. Moreover, in a pancreatic cell model, ciclopirox was found to decrease caspases, a family of cysteine proteases, by forcing the cells to elevate the cleavage level of procaspase 3 [46].

During an infection, $P$. aeruginosa can adhere to host epithelial cells through the binding of its flagellum which is essential for the swimming and swarming motility of the organism [47]. The four pili localized at a cell pole of the organism are involved in twitching and swarming motility, as well as in the formation of biofilms [45]. Treatment with $9 \mu \mathrm{g} / \mathrm{ml}$ of ciclopirox resulted in decrease of twitching and swarming motility in $37.5 \%$ and $85 \%$ of the isolates, respectively (Table 3). Similar results were previously proven among Salmonella typhimurum strains where ciclopirox was found to decrease the bacterial motility by $91.4 \%$ compared to a control motile strain [48].

Twitching motility is an important factor in the development of biofilm, where highly organized structured communities of bacteria attached to one another and to a surface decrease the penetration of antibiotics and host defense molecules [49]. A percentage of $92 \%$ of the isolates under test were biofilm formers with different degrees of strength (Fig. 1). When ten strong to moderate biofilm formers were tested quantitatively, the fold decrease in biofilm formation ranged from 1.5 to 4.5 -fold after ciclopirox treatment (Fig. 3). Similarly, a study investigating the effects of limiting iron levels in P. aeruginosa isolates found that biofilm development was significantly decreased by iron removal [50]. Disruption of biofilm formation is certainly a desirable goal that might prevent the repelling of antibiotics by biofilm structures of $P$. aeruginosa.

The effect of overnight treatment with ciclopirox on the expression of virulence genes aprA and phzA1 among ten selected isolates of $P$. aeruginosa was measured by quantitative RT-PCR (Fig. 4). The levels of expression of the selected housekeeping gene; rpsl, a $30 \mathrm{~S}$ ribosomal protein, did not change when cells were treated with subinhibitory concentrations of ciclopirox. This indicated that essential functions of the bacterial cells were not directly affected by treatment with this drug. However, the fact that genes encoding alkaline protease production and pyocyanin biosynthesis (aprA) and (phzA1), respectively, were downregulated in the presence of ciclopirox (Fig. 4) showed that this drug has multiple direct or indirect effects on the cells. It was interesting that although most of the strains treated with ciclopirox experienced downregulation with variable significance regarding phzA1 gene, the gene was markedly upregulated in PA10 and PA 26 (Fig. 4B). This can be explained by the fact that pyocyanin production in $P$. aeruginosa is a complex process involving two almost identical operons termed phz1 and phz2, which drive the production of phenazine-1-carboxylic acid which is further converted to pyocyanin [51].

The downregulatory effect of ciclopirox on genes encoding alkaline protease and pyocyanin production in $P$. aeruginosa has not been reported yet in the literature. Thus, it needs further studies as it seems to be an encouraging pathway that might account for the antipseudomonal activity of ciclopirox in vivo.

Due to the current interest in ciclopirox for treatment of hematological malignancies such as multiple myeloma [52], systemic administration of this drug has been investigated in clinical trials with a resultant satisfactory drug safety profile and an adequate absorption following oral administration [53]. Calculation of the appropriate clinical dose and assessment of therapeutic index will be certainly required as a further step to permit the repositioning of ciclopirox from its role as merely a topical antifungal agent to a promising virulence-modifying agent against one of the most problematic Gramnegative pathogens, $P$. aeruginosa.

\section{Conflict of Interest}

The authors have no financial conflicts of interest to declare.

\section{References}

1. Heras B, Scanlon MJ, Martin JL. 2014. Targeting virulence not viability in the search for future antibacterials. Br. J. Clin. Pharmacol. 79: 208-215.

2. Carlson-Banning KM, Chou A, Liu Z, Hamill RJ, Song Y, Zechiedrich L. 2013. Toward repurposing ciclopirox as an antibiotic against drug-resistant Acinetobacter baumannii, Escherichia coli, and Klebsiella pneumoniae. PLoS One 8: e69646.

3. Sonthalia S, Agrawal M. 2018. Topical ciclopirox - recalling a for- 
gotten ally in the fight against cutaneous mycoses. EC Microbiology 14: 515-534.

4. Alnour TMS, Ahmed-Abakur EH. 2017. Multidrug resistant Pseudomonas $(P)$ aeruginosa: medical impact, pathogenicity, resistance mechanisms and epidemiology. JSM Microbiology 5: 1046.

5. Strateva T, Mitov I. 2011. Contribution of an arsenal of virulence factors to pathogenesis of Pseudomonas aeruginosa infections. Ann. Microbiol. 61: 717-732.

6. Gad GF, El-Domany RA, Zaki S, Ashour HM. 2007. Characterization of Pseudomonas aeruginosa isolated from clinical and environmental samples in Minia, Egypt: prevalence, antibiogram and resistance mechanisms. J. Antimicrob. Chemother. 60: 1010-1017.

7. Aboushleib HM, Omar HM, Abozahra R, Elsheredy A, Baraka K. 2015. Correlation of quorum sensing and virulence factors in Pseudomonas aeruginosa isolates in Egypt. J. Infect. Dev. Ctries. 9: 1091-1099.

8. Overhage J, Bains M, Brazas MD, Hancock RE. 2008. Swarming of Pseudomonas aeruginosa is a complex adaptation leading to increased production of virulence factors and antibiotic resistance. J. Bacteriol. 190: 2671-2679.

9. van't Wout EF, van Schadewijk A, van Boxtel R, Dalton LE, Clarke $\mathrm{HJ}$, Tommassen J, et al. 2015. Virulence factors of Pseudomonas aeruginosa induce both the unfolded protein and integrated stress responses in airway epithelial cells. PLoS Pathog. 11: e1004946.

10. Pereira SG, Rosa AC, Ferreira AS, Moreira LM, Proenca DN, Morais PV, et al. 2014. Virulence factors and infection ability of Pseudomonas aeruginosa isolates from a hydropathic facility and respiratory infections. J. Appl. Microbiol. 116: 1359-1368.

11. Kiska DL, Gilligan PH. 2003. Pseudomonas, pp. 719-728. In Murray PR, Baron EJ, Jorgensen JH, Pfaller MA, Yolken RH (eds.), Manual of Clinical Microbiology, 8th Ed. American Society of Microbiology, Washington, D.C.

12. Clinical and Laboratory Standards Institute. 2015. Performance Standards for Antimicrobial Susceptibility Testing; Twenty-Fifth Informational Supplement. CLSI document M100-S25. Clinical and Laboratory Standards Institute, 950 West Valley Road, Suite 2500, Wayne, Pennsylvania 19087 USA.

13. Clinical and Laboratory Standards Institute. 2006. Performance Standards for Antimicrobial Susceptibility Testing; Sixteenth Informational Supplement. CLSI document M100-S16. Clinical and Laboratory Standards Institute, 940 West Valley Road, Suite 1400, Wayne, Pennsylvania 19087-1898 USA.

14. Ekanayaka SA, McClellan SA, Barrett RP, Kharotia S, Hazlett LD. 2016. Glycyrrhizin reduces HMGB1 and bacterial load in Pseudomonas aeruginosa Keratitis. Invest. Ophthalmol. Vis. Sci. 57: 57995809.

15. O'Toole GA, Pratt LA, Watnick PI, Newman DK, Weaver VB, Kolter R. 1999. Genetic approaches to study of biofilms. Methods Enzymol. 310: 91-109.

16. Merritt JH, Kadouri DE, O'Toole GA. 2011. Growing and analyzing static biofilms. Curr. Protoc. Microbiol. 22: 1-8.

17. Quiblier C, Zinkernagel AS, Schuepbach RA, Berger-Bachi B, Senn
MM. 2011. Contribution of SecDF to Staphylococcus aureus resistance and expression of virulence factors. BMC Microbiol. 11: 72.

18. King EO, Ward YM, Raney DE. 1954. Two simple media for the demonstration of pyocyanin and fluorescein. J. Lab. Clin. Med. 44: 301-307.

19. United States Pharmacopia. 2008. Microbial Limit Tests. pp. 24122745. US Pharmacopeial Convention Inc. 31st Ed. Rockville: 19.

20. Essar DW, Eberly L, Hadero A, Crawford IP. 1990. Identification and characterization of genes for a second anthranilate synthase in Pseudomonas aeruginosa: interchangeability of the two anthranilate synthases and evolutionary implications. J. Bacteriol. 172: 884-900.

21. Essar DW, Eberly L, Han CY, Crawford IP. 1990. DNA sequences and characterization of four early genes of the tryptophan pathway in Pseudomonas aeruginosa. J. Bacteriol. 172: 853-866.

22. Rust L, Messing CR, Iglewski BH. 1994. Elastase assays. Methods Enzymol. 235: 554-562.

23. Rampioni G, Schuster M, Greenberg EP, Zennaro E, Leoni L. 2009. Contribution of the RsaL global regulator to Pseudomonas aeruginosa virulence and biofilm formation. FEMS Microbiol. Lett. 301: 210-217.

24. Lenz AP, Williamson KS, Pitts B, Stewart PS, Franklin MJ. 2008. Localized gene expression in Pseudomonas aeruginosa biofilms. Appl. Environ. Microbiol. 74: 4463-4471.

25. Jazayeri JA, Nguyen K, Kotsanas D, Schneiders F, Tan C, Jazayeri $M$, et al. 2016. Comparison of virulence factors in Pseudomonas aeruginosa strains isolated from cystic fibrosis patients. J. Med. Microb. Diagn. 5: 242.

26. Pfaffl MW. 2001. A new mathematical model for relative quantification in real-time RT-PCR. Nucleic Acids Res. 29: e45.

27. Fernandez L, Breidenstein EB, Song D, Hancock RE. 2012. Role of intracellular proteases in the antibiotic resistance, motility, and biofilm formation of Pseudomonas aeruginosa. Antimicrob. Agents Chemother. 56: 1128-1132.

28. Driscoll JA, Brody SL, Kollef MH. 2007. The epidemiology, pathogenesis and treatment of Pseudomonas aeruginosa infections. Drugs. 67: 351-368.

29. Maatallah M, Cheriaa J, Backhrouf A, Iversen A, Grundmann H, Do T, et al. 2011. Population structure of Pseudomonas aeruginosa from five Mediterranean countries: evidence for frequent recombination and epidemic occurrence of CC235. PLoS One 6: e25617.

30. Woodford N, Wareham DW, Guerra B, Teale C. 2014. Carbapenemase-producing Enterobacteriaceae and non-Enterobacteriaceae from animals and the environment: an emerging public health risk of our own making? J. Antimicrob. Chemother. 69: 287-291.

31. Falagas ME, Koletsi PK, Bliziotis IA. 2006. The diversity of definitions of multidrug-resistant (MDR) and pandrug-resistant (PDR) Acinetobacter baumannii and Pseudomonas aeruginosa. J. Med. Microbiol. 55: 1619-1629.

32. Abaza A. 2010. Multidrug resistant Pseudomonas aeruginosa in a health care setting in Alexandria. Bulletin of High Institute of Public Health 40: 333-347.

33. Mustafa MH, Chalhoub H, Denis O, Deplano A, Vergison A, 
Rodriguez-Villalobos H, et al. 2016. Antimicrobial susceptibility of Pseudomonas aeruginosa isolated from cystic fibrosis patients in Northern Europe. Antimicrob. Agents Chemother. 60: 6735-6741.

34. Hachem RY, Chemaly RF, Ahmar CA, Jiang Y, Boktour MR, Rjaili $\mathrm{GA}$, et al. 2007. Colistin is effective in treatment of infections caused by multidrug-resistant Pseudomonas aeruginosa in cancer patients. Antimicrob. Agents Chemother. 51: 1905-1911.

35. Falagas ME, Kasiakou SK. 2005. Colistin: the revival of polymyxins for the management of multidrug-resistant Gram-negative bacterial infections. Clin. Infect. Dis. 40: 1333-1341.

36. Brown D. 2015. Antibiotic resistance breakers: can repurposed drugs fill the antibiotic discovery void? Nat. Rev. Drug Discov. 14: 821-832.

37. Jue SG, Dawson GW, Brogden RN. 1985. Ciclopirox olamine 1\% cream. A preliminary review of its antimicrobial activity and therapeutic use. Drugs 29: 330-341.

38. Subissi A, Monti D, Togni G, Mailland F. 2010. Ciclopirox: recent nonclinical and clinical data relevant to its use as a topical antimycotic agent. Drugs 70: 2133-2152.

39. Abrams BB, Hanel H, Hoehler T. 1991. Ciclopirox olamine: a hydroxypyridone antifungal agent. Clin. Dermatol. 9: 471-477.

40. Korting HC, Grundmann-Kollmann M. 1997. The hydroxypyridones: a class of antimycotics of its own. Mycoses 40: 243-247.

41. Kruse R, Hengstenberg W, Hanel H, Raether W. 1991. Studies for the elucidation of the mode of action of the antimycotic hydroxypyridone compound, rilopirox. Pharmacology 43: 247255.

42. Ostroff RM, Vasil Al, Vasil ML. 1990. Molecular comparison of a nonhemolytic and a hemolytic phospholipase $C$ from Pseudomonas aeruginosa. J. Bacteriol. 172: 5915-5923.

43. Niewerth M, Kunze D, Seibold M, Schaller M, Korting HC, Hube B. 2003. Ciclopirox olamine treatment affects the expression pattern of Candida albicans genes encoding virulence factors, iron metabolism proteins, and drug resistance factors. Antimicrob. Agents Chemother. 47: 1805-1817.

44. Fuse K, Fujimura S, Kikuchi T, Gomi K, lida Y, Nukiwa T, Watanabe
A. 2013. Reduction of virulence factor pyocyanin production in multidrug-resistant Pseudomonas aeruginosa. J. Infect. Chemother. 19: 82-88.

45. Kipnis E, Sawa T, Wiener-Kronish J. 2006. Targeting mechanisms of Pseudomonas aeruginosa pathogenesis. Med. Mal. Infect. 36: 78-91.

46. Mihailidou C, Papakotoulas P, Papavassiliou AG, Karamouzis MV. 2018. Superior efficacy of the antifungal agent ciclopirox olamine over gemcitabine in pancreatic cancer models. Oncotarget 9: 10360-10374.

47. Miao EA, Andersen-Nissen E, Warren SE, Aderem A. 2007. TLR5 and Ipaf: dual sensors of bacterial flagellin in the innate immune system. Semin. Immunopathol. 29: 275-288.

48. Malapaka VR, Barrese AA, Tripp BC. 2007. High-throughput screening for antimicrobial compounds using a 96-well format bacterial motility absorbance assay. J. Biomol. Screen. 12: 849854.

49. Bjarnsholt T, Tolker-Nielsen T, Hoiby N, Givskov M. 2010. Interference of Pseudomonas aeruginosa signalling and biofilm formation for infection control. Expert. Rev. Mol. Med. 12: e11.

50. O'May CY, Sanderson K, Roddam LF, Kirov SM, Reid DW. 2009. Iron-binding compounds impair Pseudomonas aeruginosa biofilm formation, especially under anaerobic conditions. J. Med. Microbiol. 58: 765-773.

51. Higgins S, Heeb S, Rampioni G, Fletcher MP, Williams P, Camara M. 2018. Differential regulation of the phenazine biosynthetic operons by quorum sensing in Pseudomonas aeruginosa PAO1N. Front Cell Infect. Microbiol. 8: 252.

52. Weir SJ, Patton L, Castle K, Rajewski L, Kasper J, Schimmer AD. 2011. The repositioning of the anti-fungal agent ciclopirox olamine as a novel therapeutic agent for the treatment of haematologic malignancy. J. Clin. Pharm. Ther. 36: 128-134.

53. Minden MD, Hogge DE, Weir SJ, Kasper J, Webster DA, Patton L, et al. 2014. Oral ciclopirox olamine displays biological activity in a phase I study in patients with advanced hematologic malignancies. Am. J. Hematol. 89: 363-368. 